\section{Marine bisindole alkaloid: A potential apoptotic inducer in human cancer cells}

\author{
Sara Salucci, ${ }^{1}$ Sabrina Burattini, ${ }^{1}$ \\ Francesca Buontempo, ${ }^{2}$ Ester Orsini, ${ }^{2}$ \\ Lucia Furiassi, ${ }^{1}$ Michele Mari, ${ }^{1}$ \\ Simone Lucarini, ${ }^{1}$ Alberto M. Martelli, ${ }^{2}$ \\ Elisabetta Falcieri $^{1}$ \\ ${ }^{1}$ Department of Biomolecular Sciences, \\ University of Urbino \\ ${ }^{2}$ Department of Biomedical and \\ Neuromotor Sciences, University \\ of Bologna, Italy
}

\begin{abstract}
Marine organisms such as corals, sponges and tunicates produce active molecules which could represent a valid starting point for new drug development processes. Among the various structural classes, the attention has been focused on 2,2-bis(6bromo-3-indolyl) ethylamine, a marine alkaloid which showed a good anticancer activity against several tumor cell lines. Here, for the first time, the mechanisms of action of 2,2-bis(6-bromo-3-indolyl) ethylamine have been evaluated in a U937 tumor cell model. Morpho-functional and molecular analyses, highlighting its preferred signaling pathway, demonstrated that apoptosis is the major death response induced by this marine compund. Chromatin condensation, micronuclei formation, blebbing and in situ DNA fragmentation, occurring through caspase activation (extrinsic and intrinsic pathways), were observed. In particular, the bisindole alkaloid induces a mitochondrial involvement in apoptosis machinery activation with Blc-2/Bcl-x down-regulation and Bax upregulation. These findings demonstrated that 2,2-bis(6-bromo-3-indolyl) ethylamine alkaloid-induced apoptosis is regulated by the Bcl-2 protein family upstream of caspase activation.
\end{abstract}

\section{Introduction}

Apoptosis, the most well-characterized form of programmed cell death, has crucial roles in normal and pathological states, including cancer. ${ }^{1}$ It can be triggered by a variety of physiological and pathological stimuli and it is routed through two main pathways, the extrinsic and the intrinsic one. The first pathway, such as Fas and other members of the tumor-necrosis factor (TNF) receptor family, is receptor-dependent, whereas the intrinsic one is activated by intracellular events which induce the release of pro-apoptotic factors from the mitochondria. Mitochondrial membrane permeability alteration is usually accompanied by the release of cytochrome $\mathrm{c}$ and finally by the activation of caspase- $9,-8$ and -3 . $^{2}$ Mitochondrial membrane integrity is afforded by the complex of Bcl-2 proteins, whose expression regulates the intrinsic apoptosis route, ${ }^{3}$ controlling the release of mitochondrial proteins into the cytoplasm. ${ }^{4}$

The intrinsic pathway is activated by various stimuli, including growth factor deprivation, oxidants, $\mathrm{Ca}^{2+}$ overload, oncogene activation, DNA-damaging agents or anticancer drugs, which usually induce apoptosis following the cytochrome c/Apaf1/caspase-9 intrinsic pathway. ${ }^{5}$ In addition to cytochrome c, mitochondria release endonuclease G, AIF (a death modulating flavoprotein) and other proteins, some of which may promote caspase-independent cell death. 6,7

Over the past decade, significant advances have been made in discovery and validation of several types of novel cancer therapeutics which could act as promising apoptosis-inducing agents. Marine natural products show potent activity and selectivity against a wide spectrum of pharmacological targets and their unprecedented structures are often an important source of lead compounds in drug discovery and development. ${ }^{8,9}$ Among the various structural classes, the marine bisindole alkaloids have received much attention due to the significant cytotoxicity, antineoplastic and antimicrobial activities. ${ }^{10}$ In particular, 2,2-bis(6bromo-3-indolyl) ethylamine (BrBIn, Figure 1), isolated from the Californian tunicate Didemnum candidum and the New Caledonian sponge Orina, ${ }^{11,12}$ has shown high cytotoxicity against several tumor cell lines such as U937 human leukemia, ${ }^{13}$ MCF-7 human breast and Caco-2 human epithelial colorectal cells. ${ }^{14}$

Cytofluorimetric analyses have already shown the presence of an apoptotic population identified through sub- $\mathrm{G}_{1}$ peak, treating cancer cells with BrBIn. ${ }^{13}$ Moreover, the apoptotic activity is common among 3,3'diindolylmethane scaffold containing molecules. ${ }^{15-17}$ However, the mechanism of action in inducing cell death of BrBIn has not yet been explored. As part of our ongoing research program in apoptosis, we report herein molecular and morpho-funtional analyses of U937 cell line treated with BrBIn highlighting the signaling pathways and describing the ultrastructural changes. Moreover, BrBIn was conjugated with a fluorescent tag (NBD-BrBIn, Figure 1) to monitor its distribution inside normal and apoptotic cells in real time.
Correspondence: Dr. Sara Salucci, Department of Biomolecular Sciences, University of Urbino, via Ca’ Le Suore 2, 61029 Urbino, Italy.

E-mail: sara.salucci@uniurb.it

Key words: Marine alkaloid; brominated bisindole; chromatin condensation; caspases; bcl-2 proteins; NBD-tagged bisindole.

Acknowledgments: This work has been possible thanks to the DISB 2017 Enhancement Project of the University of Urbino, Italy. A particular thanks to the TESCAN group for granting us the opportunity to test the multimodal holographic microscope Q-PHASE.

Received for publication: 12 December 2017 Accepted for publication: 14 February 2018.

This work is licensed under a Creative Commons Attribution-NonCommercial 4.0 International License (CC BY-NC 4.0).

(C) Copyright S. Salucci et al., 2018

Licensee PAGEPress, Italy

European Journal of Histochemistry 2018; 62:2881 doi:10.4081/ejh.2018.2881

\section{Materials and Methods}

\section{Chemicals}

4-Chloro-7-nitrobenzofurazan (NBD) and all organic solvents used in this study were purchased from Sigma-Aldrich. Prior to use, acetonitrile was dried with molecular sieves with an effective pore diameter of $4 \AA$. Column chromatography purifications were performed under "flash" conditions using Merck 230-400 mesh silica gel. Analytical thin-layer chromatography (TLC) was carried out on Merck silica gel plates (silica gel $60 \mathrm{~F}_{254}$ ), which were visualized by exposure to ultraviolet light and an aqueous solution of cerium ammonium molybdate (CAM). ESI-MS spectra were recorded with a Waters Micromass ZQ spectrometer in a negative mode using a nebulizing nitrogen gas at $400 \mathrm{~L} / \mathrm{min}$ and a temperature of $250^{\circ} \mathrm{C}$, cone flow $40 \mathrm{~mL} / \mathrm{min}$, capillary 3.5 $\mathrm{kV}$ and cone voltage $60 \mathrm{~V}$; only molecular ion $[\mathrm{M}-\mathrm{H}]$ - is given. ${ }^{1} \mathrm{H}$ NMR and ${ }^{13} \mathrm{C} \mathrm{NMR}$ spectra were recorded on a Bruker AC 400 or 100 , respectively, spectrometer and analyzed using the TopSpin software package. Chemical shifts were measured by using the central peak of the solvent.

\section{Chemistry}

BrBIn was synthesized as reported by Mari et al. ${ }^{13}$ BrBIn has been conjugated with NBD tag, a green fluorescent dye. Synthesis of $N$-[2,2-bis(6-bromo- $1 H$-indol3-yl)ethyl]-7-nitrobenzo[c][1,2,5]oxadia- 
zol-4-amine (NBD-BrBIn).

A solution of 4-chloro-7-nitrobenzofurazan (42 $\mathrm{mg}, 0.21 \mathrm{mmol}, 1 \mathrm{eq}$.) in dry acetonitrile $(4.2 \mathrm{~mL})$ was added dropwise to a mixture of BrBIn (99 mg, $0.23 \mathrm{mmol}, 1.1$ eq.) and $\mathrm{Na}_{2} \mathrm{CO}_{3}(134 \mathrm{mg}, 1.26 \mathrm{mmol}, 6$ eq.) in dry acetonitrile (10.5 mL, 0.016 M) under nitrogen atmosphere. The mixture was stirred at room temperature for $24 \mathrm{~h}$. The solvent was removed under reduced pressure and the residue was dissolved in 50 $\mathrm{mL}$ of dichloromethane. The organic solution was washed with $20 \mathrm{~mL}$ of $\mathrm{NaHCO}_{3}$ saturated solution and $20 \mathrm{~mL}$ of brine. The organic phase was dried over $\mathrm{Na}_{2} \mathrm{SO}_{4}$ and the solvent was removed under reduced pressure. The residue was purified by flash chromatography on silica gel (cyclohexane / ethyl acetate, 7:3) to give NBD-BrBIn as a red solid (105 mg, $0.18 \mathrm{mmol}, 84 \%$ yield). Melting point $=179-181^{\circ} \mathrm{C}$. TLC: $\mathrm{Rf}=0.70$ (dichloromethane / methanol / trimethylamine, 90:9:1). MS (ESI): m/z (\%) 593 (50), 595 (100), 597 (50) [M-H]-. ${ }^{1} \mathrm{H}$ NMR $\left(\right.$ DMSO $\left._{6}, 293 \mathrm{~K}\right) \delta=4.22(\mathrm{~d}, 2 \mathrm{H}, J=6.0$ $\mathrm{Hz}, \mathrm{CHCH}_{2} \mathrm{NHR}$ ), 4.98 (dd, $1 \mathrm{H}, J_{1}=J_{2}=$ $\left.6.0 \mathrm{~Hz}, \mathrm{CHCH}_{2} \mathrm{NHR}\right), 6.40$ (d, $1 \mathrm{H}, J=9.0$ $\left.\mathrm{Hz}, \mathrm{ArH}^{2}\right), 6.97$ (d, $2 \mathrm{H}, J=8.5 \mathrm{~Hz}, \mathrm{ArH}^{5}$ ), $7.36\left(\mathrm{~d}, 2 \mathrm{H}, J=8.5 \mathrm{~Hz}, \mathrm{ArH}^{4}\right), 7.43(\mathrm{~s}, 2 \mathrm{H}$, $\left.\mathrm{ArH}^{2}\right), 7.49$ (s, 2H, $\left.\mathrm{ArH}_{7}\right), 8.40(\mathrm{~d}, 1 \mathrm{H}, J=$ $\left.9.0 \mathrm{~Hz}, \mathrm{ArH}^{3}\right), 9.55$ (s, $\left.1 \mathrm{H}, \mathrm{CHCH}_{2} \mathrm{NHR}\right)$, 11.07 (s, 2H, NH). ${ }^{13} \mathrm{C}$ NMR (DMSO-d 6 , $293 \mathrm{~K}) \delta=33.0,48.5,99.9,114.2,114.4$, $116.0,120.9,120.9,121.6,124.4,126.0$, $137.7,138.1144 .5,144.8,145.5,170.8$ ppm.

\section{Cell culture}

U937 human myelomonocytic lymphoma cell line, grown in RPMI 1640 (25 $\mathrm{cm}^{2}$ flasks for electron microscopy and western blotting; multiwall with 6 well for confocal microscopy) and supplemented with $10 \%$ heat-inactivated fetal bovine serum, $2 \mathrm{mM}$ glutamine, $1 \%$ antibiotics, was maintained at $37^{\circ} \mathrm{C}$ in humidified air with $5 \% \mathrm{CO}_{2}{ }^{18}$ and cell behavior was monitored with the Inverted Microscopy (IM; Eclipse TE2000-S Nikon; objective 10x).

\section{Apoptosis induction}

For the induction of apoptosis, cells (seeded at $1 \times 10^{6}$ cells $/ \mathrm{mL}$ ) were exposed to BrBIn at various concentrations $(5 \mu \mathrm{M}, 7.5$ $\mu \mathrm{M}, 10 \mu \mathrm{M}$ ) for $24 \mathrm{~h}$. Trypan blue (TB) exclusion assay ${ }^{19}$ has been used to evaluate living and dead cells in control condition and in treated samples. For this analysis, the Neubauer chamber has been used.

\section{Transmission electron microscopy}

U937 pellets were immediately fixed in $2.5 \%$ glutaraldehyde in $0.1 \mathrm{M}$ in phosphate buffer and then post-fixed in $1 \% \mathrm{OsO}_{4}$ in the same buffer, dehydrated with ethanol and embedded in araldite as described in Salucci et al..$^{20}$ For ultrastructural analysis, thin sections, collected on nickel grids and stained with uranyl acetate and lead citrate, were observed with an electron microscope (Philips CM10, 80KV, FEI Italia Srl, Milan, Italy).

\section{Confocal laser scanning microscopy}

\section{TUNEL}

Control and treated cells were fixed with $4 \%$ paraformaldehyde in phosphate buffer saline (PBS) pH 7.4 for $30 \mathrm{~min}$, then deposited on poly-lysinated coverslips in Petri dishes overnight at $4^{\circ} \mathrm{C}$. After PBS washing, samples were permeabilized with a 2:1 mixture of ethanol and acetic acid for $5 \mathrm{~min}$ at $-20^{\circ} \mathrm{C} .{ }^{21}$ For the TUNEL technique, all reagents were part of the Apoptag Plus kit (D.B.A., Oncor, Dallas, TX, USA) and procedures were carried out according to the manufacturer's instructions and as described in Salucci et al..$^{20}$ Finally, slides were mounted with an antifading medium. ${ }^{22}$ Specimens were observed with a Leica TCS-SP5 confocal laser scanning microscope (CLSM) connected to a DMI 6000 $\mathrm{CS}$ inverted microscope (Leica Microsystems CMS GmbH, Mannheim, Germany); excitation was at $488 \mathrm{~nm}$ and emission signals were detected at $517 \mathrm{~nm}$.

\section{Mitochondrial behavior}

To monitor mitochondrial behavior, fresh cells were treated with 10-nonyl acridine orange (NAO) and JC1 probe for evaluating mitochondria membrane integrity and potential membrane functionality, respectively. In particular, NAO binds cardiolipin, a phospholipid located in the inner mitochondrial membrane permitting to identify peroxidation events. Fresh cells were exposed to $50 \mathrm{nM}$ NAO for $10 \mathrm{~min}$ at room temperature or to $\mathrm{JC} 1$ for $20 \mathrm{~min}$ at $37^{\circ} \mathrm{C} .{ }^{23}$ Samples were observed through a Leica TCS-SP5 Confocal connected to a DMI 6000 CS Inverted Microscope (Leica Microsystems CMS GmbH; objectives 40x and $60 \mathrm{x}$ ); excitation was at $488 \mathrm{~nm}$ (FITC and NAO); emission signals were detected at $519 \mathrm{~nm}$ (NAO) or $525 \mathrm{~nm}$ (JC1). CLSM images are presented as single-plane images or Z-stack projections. ${ }^{24}$

\section{Quantitative phase imaging (Q-PHASE)}

Multimodal holographic microscope QPHASE (Tescan, Brno, Czech Republic) permits to observe live and fixed cells without any additional staining. ${ }^{25,26}$ It is based on a robust inverted transmission microscope platform. The whole system is situated in a microscope incubator and includes multiple imaging modes with fully integrated fluo- rescence module, simulated DIC (differential interference contrast) and brightfield imaging options. Cells were seeded $\left(1 \times 10^{5}\right.$ cells $/ 200 \mu \mathrm{L}$ ) and grown in Flow chambers -Slide I Lauer Family (Ibidi, Martinsried, Germany). Holograms were captured by a CCD camera (XIMEA MR4021 MCVELETA). The entire image reconstruction and image processing were performed in QPHASE control software. Quantitative phase images are shown in grayscale with units of $\mathrm{pg} / \mu \mathrm{m}^{2}$ that were recalculated from original radians. Nikon Plan $10 \times / 0.3$ and Nikon PlanFluor $20 \times / 0.5$ objectives were used for both holographic and fluorescence observations useful to monitor drug behavior after its administration in cells. In this case, compound BrBIn has been conjugated with a fluorescent chemical group becoming the compound NBD-BrBIn (Figure 1). After several experiments on cell viability (data not shown), a $40 \mu \mathrm{M}$ dose of NBDBrBIn, able to induce a significant apoptosis rate, has been chosen. Therefore, cells have been treated with $40 \mu \mathrm{M}$ of NBD-BrBIn and drug behavior has been monitored in vivo to evaluate its distribution in cells after $1 \mathrm{~h}$ and $24 \mathrm{~h}$. Cells were collected and fixed with $4 \%$ paraformaldehyde and, after PBS washing, they were stained with $3 \mu \mathrm{L} / \mathrm{mL}$ nuclear probe DAPI for $2 \mathrm{~min}$ and analyzed through Q-PHASE microscope.

\section{Western blotting}

Western blot analyses were performed as previously detailed. ${ }^{27}$ Cells were lysed using the M-PER Mammalian Protein Extraction Reagent, supplemented with the Protease and Phosphatase Inhibitor Cocktail (Thermo Fisher Scientific Inc., Rockford, IL, USA). Gradient gels (4\% - 20\% acrylamide) were used. Analysis with an antibody to $\beta$-actin documented equal protein loading. All the primary and secondary antibodies were from Cell Signaling Technology (Danvers, MA, USA). Proteins were detected using the Amersham ECL Prime Western Blotting Detection Reagent (GE Healthcare, Little Chalfont, UK), the ChemiDoc-It2 Imaging System and the VisionWorksLS Software for camera control setting and image capture (UVP, LLC, Upland, CA, USA).

\section{Results}

The effect of BrBIn has been evaluated at different concentrations $(5 \mu \mathrm{M}, 7.5 \mu \mathrm{M}$, $10 \mu \mathrm{M})$ after $24 \mathrm{~h}$ from the administration. Evaluating cell viability with TB, compound BrBIn is able to reduce cell viability showing a dose dependent effect (Figure 2A). To identify whether the type of death induced by bis-indole alkaloid was apoptot- 
ic or necrotic, samples have been processed for ultrastructural analyses (Figure 2). Morphological observations showed preserved nuclei and cytoplasmic organelles (Figure 2B) in untreated samples. When cells were exposed to $5 \mu \mathrm{M}$ drug concentration, a negligible number of apoptotic cells could be detected (Figure 2C), while the other ones presented a diffuse cytoplasmic vacuolization similar to autophagic complexes (Figure 2D). Typical apoptotic markers, such as cell shrinkage, cytoplasmic vacuolization, mitochondria alterations, chromatin condensation, micronuclei and secondary necrosis could be observed by increasing drug concentration to $7.5 \mu \mathrm{M}$ (Figure 2E-H). Exposing cells to $10 \mu \mathrm{M}$ concentration, cells are almost necrotic (Figure 2I), for this reason the $10 \mu \mathrm{M}$ dosage has not considered for the further experiments.

TUNEL reaction reveals no in situ DNA fragmentation in control condition (Figure 3A). Cells exposed to $5 \mu \mathrm{M}$ alkaloid dose showed few TUNEL positive nuclei (Figure 3B) and their number thereby increases after $7.5 \mu \mathrm{M}$ drug treatment (Figure $3 \mathrm{C}-\mathrm{E}$ ). In this experimental condition fluorescent staining appeared localized in the cupshaped masses (Figure 3D) and on micronuclei (Figure 3 C, E).

Western blotting showed the alkaloid ability to induce apoptotic cell death by caspase dependent mechanisms (Figure 3F). In particular, at $5 \mu \mathrm{M}$ dose no caspase activation can be observed but only a minimal increase of cleaved caspase-8. On the other hand, after $7.5 \mu \mathrm{M}$ drug exposure, caspase- 8 and -9 appeared cleaved, demonstrating the involvement of both extrinsic and intrinsic pathways, also confirmed by the caspase- 3 activation which is, as known, the executive enzyme of apoptosis. Caspase-mediated apoptotic cell death is supported by the cleavage of several key proteins required for cellular functioning and survival. ${ }^{28}$ PARP-1 is one of the well known cellular substrates of caspases and its cleavage by caspases is considered a hallmark of apoptosis. ${ }^{29}$ In addition, a higher expression of cleaved PARP assured that the apoptosis involved internucleosomal DNA fragmentation, ${ }^{30}$ and this is the case of our samples exposed to $7.5 \mu \mathrm{M}$ alkaloid dose (Figure 3F).

Since ultrastructural analyses revealed a diffuse mitochondria damage after alkaloid treatments, the mitochondrial behavior has been also investigated at CLSM through specific fluorescent probes to monitor cardiolipin state and mitochondrial membrane potential preservation. Differently from control cells (Figure 4 A,B), the treatedones presented mitochondria with structural and functional changes, as observed after NAO (Figure $4 \mathrm{C}, \mathrm{E}$ ) and JC-1 (Figure 4
$\mathrm{D}, \mathrm{F})$ staining, resulting more evident after $7.5 \mu \mathrm{M}$ exposure (Figure $4 \mathrm{E}, \mathrm{F}$ ). Thus, mitochondrial pathway involvement, furtherly demonstrated by peroxidation events and mitochondrial membrane potential alterations, suggests an important role of this organelle in our model too. In addition,

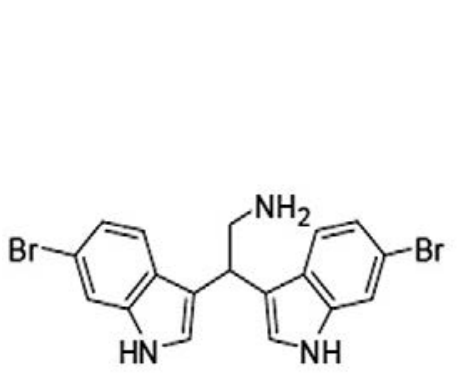

BrBIn since $\mathrm{Bax} / \mathrm{Bcl}-2$ modulation is proceeded by the collapse of mitochondrial membrane potential, which could be associated with the initiation of caspase cascade leading to cell death, ${ }^{31}$ molecular analyses have been carried out to evaluate the involvement of Bcl-2 protein family. In this study, western
Figure 1. Chemical structure of BrBIn and NBD-BrBIn.

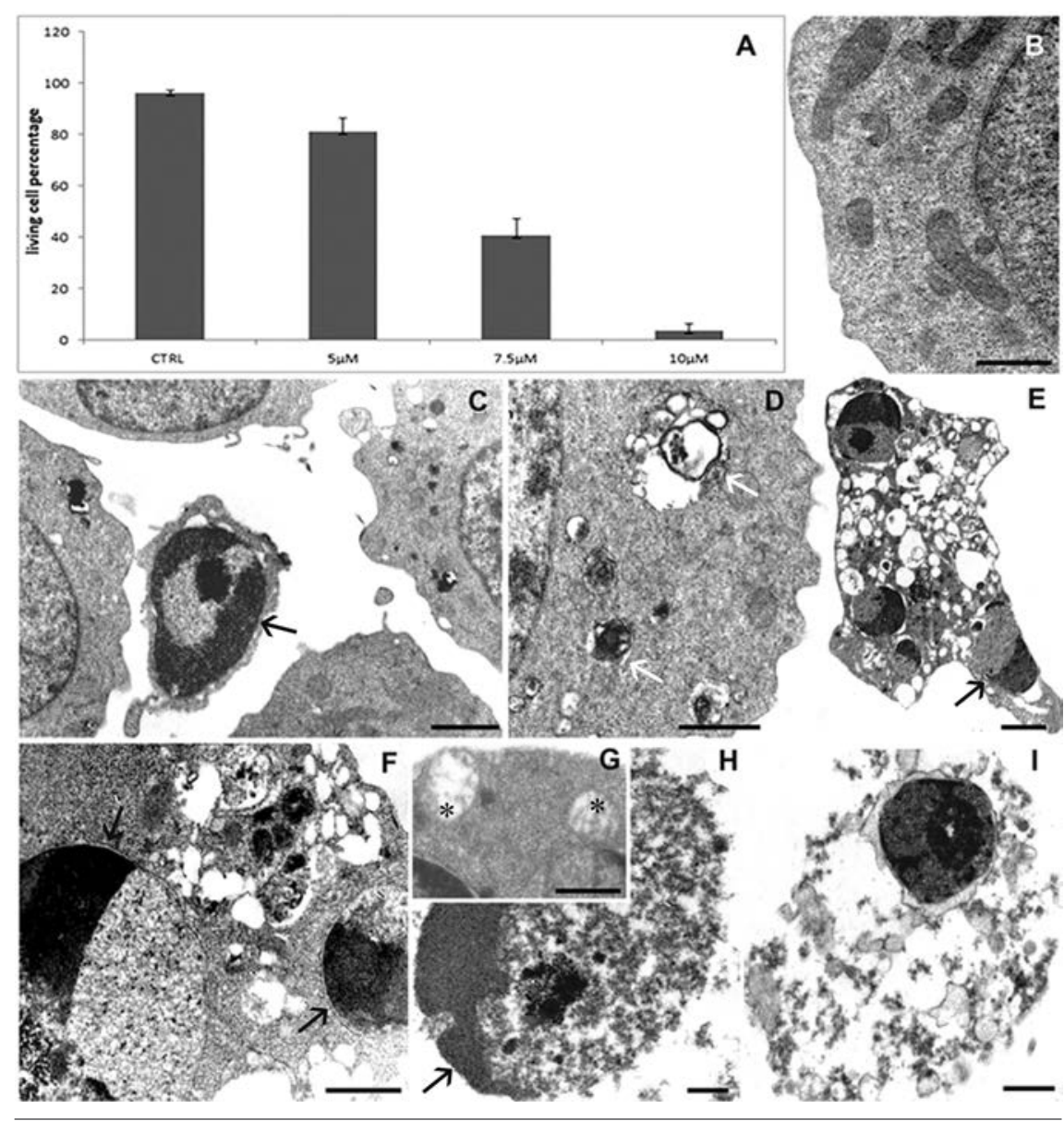

Figure 2. TB exclusion assay (A) reveals a cell viability reduction after drug administration. Data are from three separate experiments and furnished as mean $+/-$ standard deviation. TEM micrographs of U937 cells in control condition (B) and after $5 \mu \mathrm{M}(\mathrm{C}, \mathrm{D})$ or $7.5 \mu \mathrm{M}$ (E-H) or $10 \mu \mathrm{M}$ (I) alkaloid exposure. In B, a preserved morphology appears. After treatments autophagic structures (D, white arrows), apoptotic cells with condensed chromatin (C, E, F, H, black arrows) and empty mitochondria (G, asterisks) can be observed. In I, a necrotic cell is visible. Scale bars: B,D,F,I) $1 \mu \mathrm{m} ; \mathrm{C}, \mathrm{E}) 2 \mu \mathrm{m} ; \mathrm{G}, \mathrm{H}) 0.5 \mu \mathrm{m}$. 
blotting revealed Bax up-regulation and Bcl-2 and Bcl-xL down-regulation (Figure $4 \mathrm{~F}$ ), a condition favorable to apoptotic signal transduction mechanism.

Finally, BrBIn has been conjugated with a green fluorescent dye, obtaining the NBD-BrBIn compound (Figure 1). Several analyses on cell viability (data not shown) evidenced that the fluorescent chemical group added to the alkyl-amino side chain of BrBIn thereby reduced the cytotoxic activity of bis- indole alkaloid. So, NBDBrBIn must be used at $40 \mu \mathrm{M}$ dosage to obtain a considerable apoptotic effect.

Q-PHASE instrument has been useful to investigate how the fluorescent drug interacts with normal or apoptotic cells using hologram and fluorescence modality contemporary. This technique permits to detect, also without staining, the morphological apoptotic patterns. So, as shown in Figure 5, at the beginning the compound diffuses through the cytoplasm in the presence of intact and well preserved nuclei observable with DAPI staining (Figure 5 A,B). After $24 \mathrm{~h}$, a conspicuous number of cells presented apoptotic features. In these cells, NBD-BrBIn forms the punctate dots inside the cytoplasm demonstrating that its action site for apoptosis induction is not the nucleus (Figure $5 \mathrm{C}, \mathrm{D}$ ) but it could colocalize with cytoplasmic organelles like mitochondria.

\section{Discussion}

In this study, we have evaluated the anti-cancer potential of a marine bisindole alkaloid BrBIn. Previous studies have shown, through cell cycle analysis, the presence of an apoptotic population induced by BrBIn, ${ }^{13}$ but the molecular mechanisms underlying the cell death remained unexplored.

Here, for the first time, morpho-functional behavior and molecular mechanisms have been investigated in a human cancer cell line exposed to BrBIn. These findings display the potential role of sponge alkaloid as a possible apoptotic drug, demonstrating its dose dependent effect.

In U937 treated cell line apoptotic features, such as in situ DNA fragmentation, chromatin condensation and micronuclei formation, could be observed in the presence of peroxidation event increase and reduction or loss of mitochondrial membrane potential. These morpho-functional results, indirectly evidencing a possible drug interaction with the mitochondrial pathway, demonstrated by cardiolipin oxidation increase which could induce the release of pro-apoptotic proteins..$^{20}$ In addition, Q-PHASE observations clearly
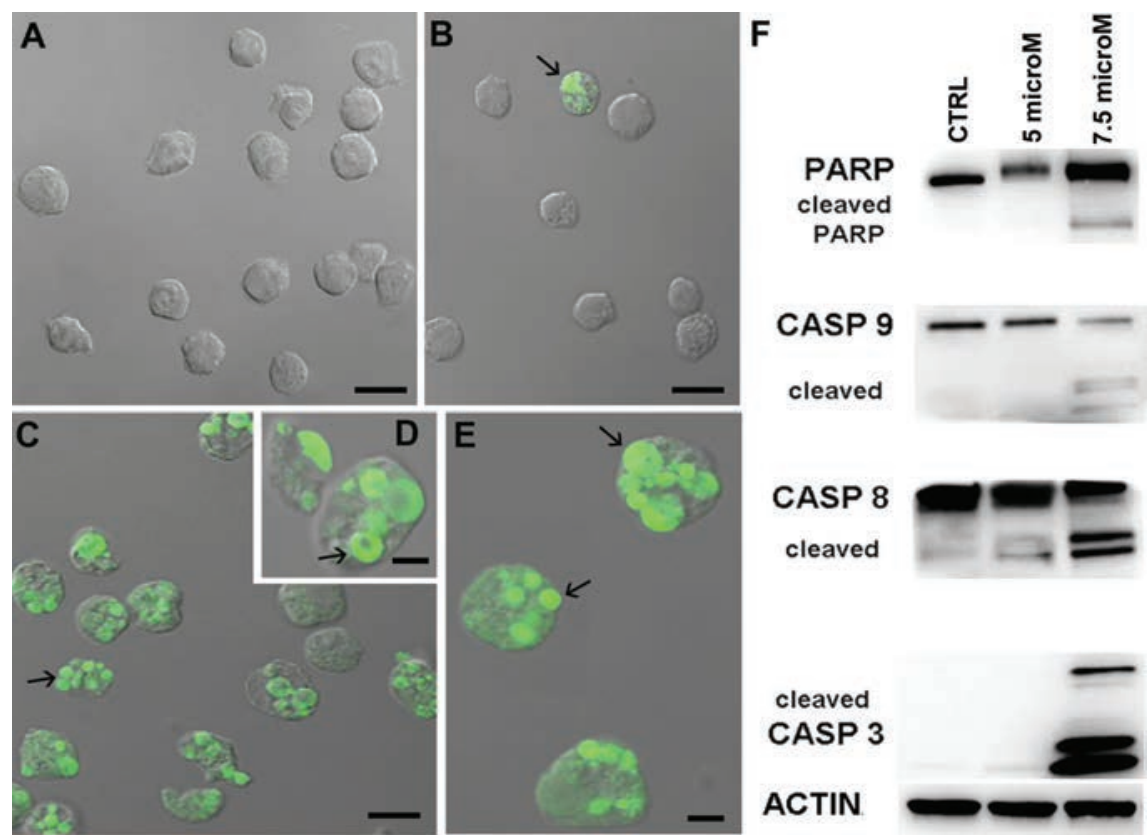

Figure 3. Control cells (A) and those exposed to $5 \mu \mathrm{M}(\mathrm{B})$ or $7.5 \mu \mathrm{M}(\mathrm{C}-\mathrm{E})$ drug concentration after TUNEL reaction, reveal a fluorescent staining localized in micronuclei (arrows). Western blotting analyses (F) of caspase-8, -9, -3 and PARP-1 which appear cleaved after treatments. Scale bars: A,B) $10 \mu \mathrm{m}$; C) $5 \mu \mathrm{m}$; D,E) $2 \mu \mathrm{m}$.
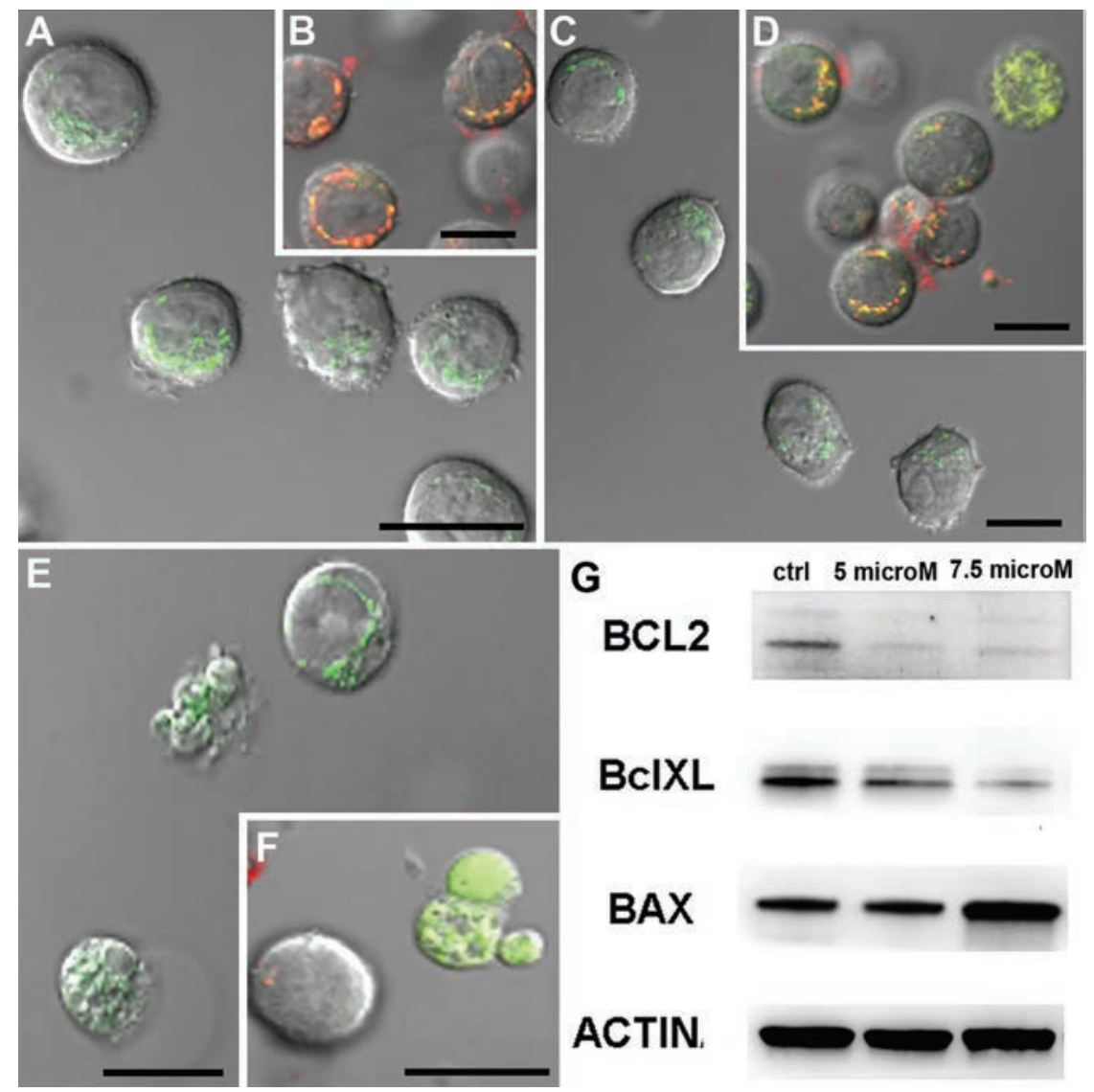

G

ctrl 5 microM 7.5 microM

BCL2

BcIXL

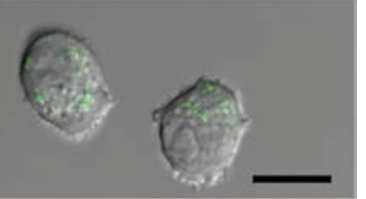

cleaved

CASP 3

ACTIN

Figure 4. NAO (A,C,E) and JC-1 (B,D,F) fluorescence images of control condition $(A, B)$ and of samples exposed to $5 \mu \mathrm{M}(\mathrm{C}, \mathrm{D})$ or $7.5 \mu \mathrm{M}$ drug concentration $(\mathrm{E}, \mathrm{F})$. NAO fluorescence decreases after treatments $(\mathrm{C}, \mathrm{E})$ and $\mathrm{JCl}$ staining $(\mathrm{D}, \mathrm{F})$ became green indicating a low mitochondrial potential. Scale bars: $10 \mu \mathrm{m}$. Western blotting analyses of Bcl-2 protein family activation $(\mathrm{G})$ evidence an up-regulation of $\mathrm{Bcl}-\mathrm{xL}$ and $\mathrm{Bax}$ after BrBIn exposure. 

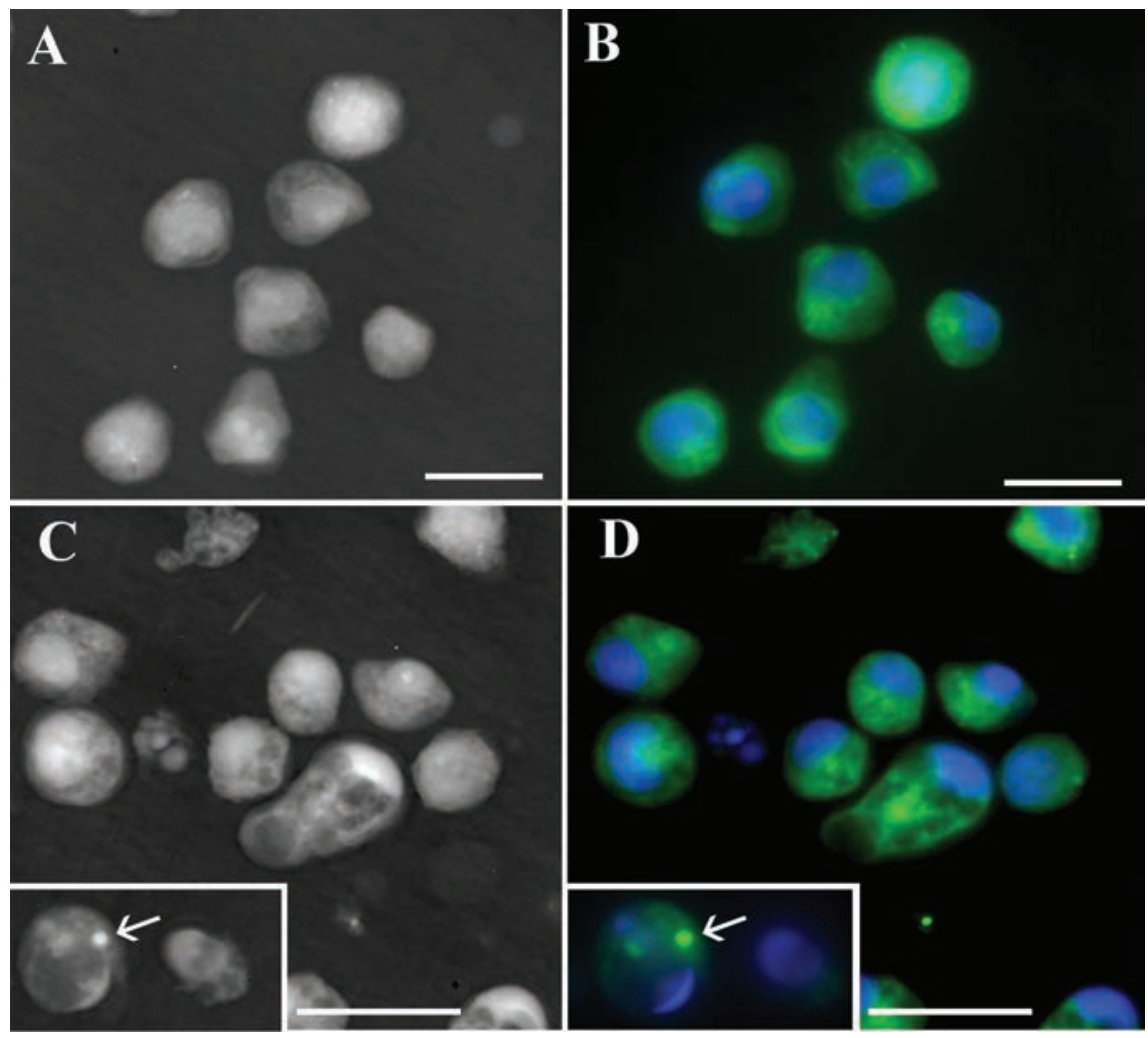

Figure 5. Q-PHASE micrographs in phase (A,C) and fluorescence modality (B,D). Cells have been treated with fluorescent alkaloid molecule after $1 \mathrm{~h}(\mathrm{~A}, \mathrm{~B})$ or $24 \mathrm{~h}(\mathrm{C}, \mathrm{D})$ and stained with DAPI to monitor nuclear behavior. Apoptotic cells are visible in $C$ and $D$, where the fluorescent compound is organized in punctate dots (arrows). Scale bars: $10 \mathrm{\mu m}$.

showed that cytoplasm is the site where the alkaloid seems to act and where it aggregates when apoptosis occurs. Western blotting analyses confirmed the mitochondrial involvement revealing the activation of the intrinsic pathway followed by caspase- 3 activation and cleavage of PARP-1. Then, our investigations have been focused on Bcl-2 family, well-known apoptosis regulators, which play a primary role in intrinsic apoptosis. ${ }^{32}$ The ratio between anti- and pro-apoptotic factors influences the occurrence of apoptosis. ${ }^{33} \mathrm{Bcl}-2$ and $\mathrm{Bcl}-\mathrm{xL}$, the anti-apoptotic factors, that block the release of cytochrome $\mathrm{c}$ from mitochondria and thus promote cell survival, are inactivated in treated sample. In contrast, Bax, a proapoptotic factor, is up-regulated after alkaloid exposure, assuring its translocation from the cytoplasm to the outer mitochondrial membrane promoting its permeabilization. In addition, caspase- 8 up-regulation may activate Bax and induce the release of cytochrome $c$ from the mitochondria, causing the cleavage of caspase- 9 and contributing to the activation of caspase- $3 .{ }^{34}$ These results suggest that sponge alkaloid BrBIn modulates the ratio between anti-apoptotic and pro-apoptotic factors, in particular by enhancing Bax expression, promoting U937 apoptotic cell death.

It is known that the success rate of chemotherapy in cancer patients depends upon Bcl-2 and other anti-apoptotic proteins for cell survival: for that reason, molecular therapies which targeted antiapoptotic Bcl-2 protein have shown potential success in killing many types of cancer. $^{35}$ Moreover, overexpression of $\mathrm{Bcl}-2$ has been shown to inhibit cisplatin-induced cell death in cancer cells. ${ }^{36}$ Thus, this sponge alkaloid, which has the ability to suppress anti-apoptotic protein of the Bcl-2 family, may become a promising candidate for cancer treatment.

\section{References}

1. Salucci S, Burattini S, Falcieri E, Gobbi P. Three-dimensional apoptotic nuclear behavior analyzed by means of Field Emission in Lens Scanning Electron Microscope. Eur J Histochem 2015;59: 539.

2. Krishna S, Low ICC, Pervaiz S. Regulation of mitochondrial metabolism: yet another facet in the biology of the oncoprotein Bcl-2. Biochem J 2011;435:545-51

3. Shamas-Din A, Brahmbhatt H, Leber B, Andrews DW. BH3-only proteins: orchestrators of apoptosis. Biochim Biophys Acta 2011;1813; 508-20.

4. Cory S, Adams JM. The Bcl2 family: regulators of the cellular life-or-death switch. Nat Rev Cancer 2002;2:647-56.

5. Kaufmann SH, Earnshaw WC. Induction of apoptosis by cancer chemotherapy. Exp Cell Res 2000;256: 42-9.

6. Kroemer G, Reed JC. Mitochondrial control of cell death. Nature Med 2000;6:513-9.

7. Zheng LC, Yang MD, Kuo CL, Lin CH, Fan MJ, Chou YC, et al. Norcantharidin-induced apoptosis of AGS human gastric cancer cells through reactive oxygen species production, and caspase- and mitochondria-dependent signaling pathways. Anticancer Res 2016;36:6031-42.

8. Governatori L, Carlucci G, Genovese S, Mollica A, Epifano F. Recent application of analytical methods to phase I and phase II drugs development: A review. Biomed Chromatogr 2012;26: 283-300.

9. Kobayashi J. Search for new bioactive marine natural products and application to drug development. Chem Pharm Bull 2016;64:1079-83

10. Veale CG, Davies-Coleman MT. Marine bi-, bis-, and trisindole alkaloids. The Alkaloids: Chemistry and Biology, Hans-Joachim Knölker, Editor. Elsevier; 2014; p. 1-64.

11. Bifulco G, Bruno I, Riccio R, Lavayre J, Bourdy G. Further brominated bisand tris- indole alakaloids from the deep-whater New Caledonian marine sponge. J Nat Prod 1995;58:1254-60.

12. Fahy E, Potts BCM, Faulkner DJ, Smith K. 6-bromotryptamine derivatives from the Gulf of California tunicate Didemnum candidum. J Nat Prod 1991; 54:564-9.

13. Mari M, Tassoni A, Lucarini S, Fanelli M, Piersanti G, Spadoni G. Brønsted acid catalyzed bisindolization of $\alpha$ amido acetals: Synthesis and anticancer activity of bis(indolyl)ethanamino derivatives. Eur J Org Chem 2014; 2014:3822-30.

14. Mantenuto S, Lucarini S, De Santi M, Piersanti G, Brandi G, Favi, G. One-pot synthesis of biheterocycles based on indole and azole scaffolds using tryptamines and 1,2-diaza-1,3-dienes as building blocks. Eur J Org Chem 2016; 2016:3193-9.

15. Bhatnagar N, Li X, Chen Y, Zhou X, Garrett SH, Guo B. 3,3'-diindolyl- 
methane enhances the efficacy of butyrate in colon cancer prevention through down-regulation of surviving. Cancer Prev Res (Phila) 2009;2:581-9.

16. Kandala PK, Wright SE, Srivastava SK. Blocking epidermal growth factor receptor activation by 3,3'-diindolylmethane suppresses ovarian tumor growth in vitro and in vivo. J Pharmacol Exp Ther 2012;341:24-32.

17. Ryan KS, Drennan CL. Divergent pathways in the biosynthesis of bisindole natural products. Chem Biol 2009;16: 351-64.

18. Salucci S, Burattini S, Battistelli M, Baldassarri V, Curzi D, Valmori A, et al. Melatonin prevents chemical-induced haemopoietic cell death. Int J Mol Sci 2014;15:6625-40.

19. Burattini S, Battistelli M, Codenotti S, Falcieri E, Fanzani A, Salucci S. Melatonin action in tumor skeletal muscle cells: an ultrastructural study. Acta Histochem 2016;118:278-85.

20. Salucci S, Baldassarri V, Canonico B, Burattini S, Battistelli M, Guescini M, et al. Melatonin behavior in restoring chemical damaged $\mathrm{C} 2 \mathrm{C} 12$ myoblasts. Microsc Res Tech 2016;79:532-40.

21. Battistelli M, Salucci S, Olivotto E, Facchini A, Minguzzi M, Guidotti S, et al. Cell death in human articular chondrocyte: a morpho-functional study in micromass model. Apoptosis 2014;19: 1471-83.

22. Battistelli M, Salucci S, Burattini S, Falcieri E. Further considerations on in vitro skeletal muscle cell death. Muscles Ligaments Tendons J 2014;3: 267-74.
23. Salucci S, Burattini, S, Giordano FM, Lucarini S, Diamantini G, Falcieri E. Further highlighting on the prevention of oxidative damage by polyphenol-rich wine extracts. J Med Food 2017;20:4 10-9.

24. Salucci S, Burattini S, Battistelli M, Buontempo F, Canonico B, Martelli AM, et al. Tyrosol prevents apoptosis in irradiated keratinocytes. J Dermatol Sci 2015;80:61-8.

25. Balvan J, Gumulec J, Raudenska, M, Krizova A, Stepka P, Babula P, et al. Oxidative stress resistance in metastatic prostate cancer: Renewal by self-eating. PLoS One 2015;10:e0145016.

26. Balvan J, Krizova A, Gumulec J, Raudenska M, Sladek Z, Sedlackova M, et al. Multimodal holographic microscopy: distinction between apoptosis and oncosis. PLoS One 2015;10:e 0121674.

27. Lonetti A, Cappellini A, Spartà AM, Chiarini F, Buontempo F, Evangelisti C. PI3K pan-inhibition impairs more efficiently proliferation and survival of $\mathrm{T}$ cell acute lymphoblastic leukemia cell lines when compared to isoform-selective PI3K inhibitors. Oncotarget 2015;6: 10399-414.

28. Castri P, Lee YJ, Ponzio T, Maric D, Spatz M, Bembry J, et al. Poly(ADPribose) polymerase- 1 and its cleavage products differentially modulate cellular protection through NF-kappaBdependent signaling. Biochim Biophys Acta 2014;1843:640-51.

29. Chaitanya GV, Steven AJ, Babu PP. PARP-1 cleavage fragments: signatures of cell-death proteases in neurodegener- ation. Cell Commun Signal 2010;8:31.

30. Mondal A, Bennett LL. Resveratrol enhances the efficacy of sorafenib mediated apoptosis in human breast cancer MCF7 cells through ROS, cell cycle inhibition, caspase 3 and PARP cleavage. Biomed Pharmacother 2016; 84:1906-14.

31. Penninger JM, Kroemer G. Mitochondria, AIF and caspases-rivaling for cell death execution. Nat Cell Biol 2003;5:97-9.

32. Volkmann N, Marassi FM, Newmeyer DD, Hanein D. The rheostat in the membrane: BCL-2 family proteins and apoptosis. Cell Death Differ 2014;21: 206-15.

33. Czabotar PE, Lessene G, Strasser A, Adams JM. Control of apoptosis by the Bcl-2 protein family: Implications for physiology and therapy. Nat Rev Mol Cell Biol 2014;15:49-63.

34. Martinou JC, Youle RJ. Mitochondria in apoptosis: Bcl-2 family members and mitochondrial dynamics. Dev Cell 2011;21:92-101.

35. Halim H, Chunhacha P, Suwanborirux K, Chanvorachote P. Anticancer and antimetastatic activities of Renieramycin M, a marine tetrahydroisoquinoline alkaloid, in human nonsmall cell lung cancer cells. Anticancer Res 2011;3:193-201.

36. Chanvorachote P, Nimmannit U, Stehlik C, Wang L, Ongpipatanakul B, Rojanakul Y. Nitric oxide regulates cell sensitivity to cisplatin-induced apoptosis through S-nitrosylation and inhibition of BCL-2 ubiquitination. Cancer Res 2006;66:6353-60. 